\title{
Demonstration of bronchial eosinophil activity in seasonal allergic rhinitis by induced plasma exudation combined with induced sputum
}

Lennart Greiff, Morgan Andersson, Christer Svensson, Margareta Linden, Per Wollmer, Carl G A Persson yield of some markers of inflammation in sputum samples.

(Thorax 1999;54:33-36)

Keywords: allergic rhinitis; $\alpha_{2}$-macroglobulin; asthma; ECP; histamine; induced sputum; plasma exudation

Allergic rhinitis and bronchial asthma frequently involve abnormalities of both the nasal and the bronchial mucosa. ${ }^{12}$ There is also an increasing awareness that in many cases the nasal disease may precede the development of asthma and, hence, that patients with allergic rhinitis may exhibit early signs of asthma. ${ }^{1-4}$ Features of asthma include bronchial hyperresponsiveness, bronchial eosinophilia, and increased levels of toxic eosinophil products in bronchial samples such as sputum. ${ }^{25}$ Importantly, eosinophil cationic protein (ECP), major basic protein (MBP), and other eosinophil derived agents have actions on airway structure and physiology which may be pathogenic in asthma. ${ }^{6}$ Seasonal allergic rhinitis has been found to be associated with bronchial hyperresponsiveness to methacholine, ${ }^{78}$ but little is known about activation of bronchial eosinophils in this disease.

With the technique of induced sputum bronchial surface material can be readily obtained for diagnostic and research purposes. However, the "waste" material appearing in the airway lumen may not reflect all important disease events in the mucosal tissue. Using induced sputum in healthy volunteers we have recently shown that histamine challenges produced acute luminal entry of $\alpha_{2}$-macroglobulin. ${ }^{9}$ In experimental studies this response has been found to reflect extravasation, lamina propria distribution, and paracellular, noninjurious, epithelial crossings of bulk plasma. ${ }^{10}$ Since plasma contains many binding proteins, including $\alpha_{2}$-macroglobulin that binds ECP (as well as many cytokines), ${ }^{11}{ }^{12}$ we have hypothesised that the induced acute luminal entry of bulk plasma may enrich the sputum sample with molecules that otherwise would have remained in the extracellular matrix of the epithelium and the lamina propria. ${ }^{10}$ Hence, by combining induced sputum with induced exudation the sputum sample content may better reflect bronchial mucosal tissue levels of important molecules. In this study the dual induction method is used to identify increased ECP levels in the bronchi of patients with seasonal allergic rhinitis. 


\section{Methods}

STUDY DESIGN

The study was of an open design. Sputum was induced in patients with birch pollen seasonal allergic rhinitis by inhalation of hypertonic saline twice before (study day -14 (4) days) and twice during the pollen season (study day 21 (2) days) where study day 1 represents the start of the pollen season. The second of each pair of sputum inductions was preceded by inhaled histamine challenge. Sputum concentrations of $\alpha_{2}$-macroglobulin and ECP were measured as indices of mucosal exudation of bulk plasma and eosinophil activation. The interval between the baseline sputum induction and the induction preceded by histamine challenge was 48 hours.

SUBJECTS

Eleven patients (nine men) aged 22-30 years with seasonal allergic rhinitis were recruited. The patients had a history of strictly birch pollen allergic rhinitis, verified by a positive skin prick test to birch pollen allergen, and no history of seasonal chest symptoms. The patients all had a baseline forced expiratory volume in one second $\left(\mathrm{FEV}_{1}\right)$ of more than $90 \%$ of the predicted $\mathrm{FEV}_{1}$. The patients had no history of perennial allergy, asthma, recent bronchial disease, or recent drug treatment. The study was approved by the local ethics committee and informed consent was obtained.

NASAL SYMPTOM SCORES

Nasal symptoms - that is, rhinorrhea, blockage, and sneezes - were scored by the patients once every day during the pollen season $(0=$ no symptoms, $1=$ mild symptoms, $2=$ moderate symptoms, and $3=$ severe symptoms).

ADMINISTRATION OF AEROSOLS

Bronchial challenges with histamine were carried out using a dosimetric aerosol delivery system based on an air jet nebuliser (Spira Electro 2, Respiratory Care Center, Hämenlinna, Finland). Aerosol delivery was set to commence after inhalation of 0.1 litres. Nebulisation then continued for $1.0 \mathrm{~s}$. The volume of each inspiration was approximately 1.0 litres and the flow rate was approximately $0.51 / \mathrm{s}$. Hypertonic saline was administered using an ultrasonic nebuliser (Aerosonic, DeVilbiss Health Care, Somerset, Pennsylvania, USA). This nebuliser generates droplets of $4 \mu \mathrm{m}$ diameter (mass median diameter for hypertonic saline $4.5 \%$ ) and the nebulisation rate is $0.3 \mathrm{ml} / \mathrm{min}$

BRONCHIAL HISTAMINE CHALLENGE

Before each histamine challenge series baseline $\mathrm{FEV}_{1}$ was recorded - that is, the highest $\mathrm{FEV}_{1}$ recorded of three consecutive tests - using an electronic spirometer (Vitalograph Compact II, Buckingham, UK). Thereafter the subjects inhaled increasing doses of histamine starting with the initial dose of $2 \mu \mathrm{g} .{ }^{9} \mathrm{FEV}_{1}$ was recorded three minutes after each histamine challenge. The inhaled dose was varied by alteration of the concentration of the nebulised solution as well as the number of inhaled breaths. Three concentrations of histamine were used: $0.4,6.0$, and $30 \mathrm{mg} / \mathrm{ml}$. The maximum number of breaths for one dose was 12. The histamine challenge series resulted in the following possible cumulative doses: 2,10 , $40,160,460,1360$, and $3160 \mu \mathrm{g}$. The challenges were continued both before and during the pollen season until a cumulative dose of $3160 \mu \mathrm{g}$ had been given or until a $20 \%$ decrease in $\mathrm{FEV}_{1}$ was achieved. Individual bronchial responsiveness was assessed at the highest dose level of histamine that could be given at both challenge occasions (before and during the season) even though further challenges were given on one of the occasions. The response was expressed as a percentage of the baseline $\mathrm{FEV}_{1}$ recorded before the histamine challenge series - that is, $\operatorname{FEV}_{1}(\%$ baseline $)$.

SPUTUM INDUCTION

Aerosolised hypertonic saline $(4.5 \%)$ was inhaled at resting ventilation rate for 40 minutes with the nose blocked using a clip. ${ }^{9}$ The patients were asked to try not to cough during this time. The subjects were then instructed to rinse their mouth three times with $20 \mathrm{ml}$ water, to clear their throats, and to cough sputum into a container. The quality of the sputum sample was assessed by its macroscopic appearance only. The sputum samples (whole expectorates) were frozen at $-20^{\circ} \mathrm{C}$ for later analysis of $\alpha_{2}$-macroglobulin and ECP.

ANALYSES OF $\alpha_{2}$-MACROGLOBULIN AND ECP The sputum samples were processed by ultrasonication for 15 minutes and centrifugation at $32000 \mathrm{~g}$ for 15 minutes. The levels of $\alpha_{2}$-macroglobulin were measured using a radioimmunoassay sensitive to $7.8 \mathrm{ng} / \mathrm{ml}^{9}$ with a correlation coefficient of $<15 \%$. The sputum levels of ECP were measured using a FEIA (Pharmacia Diagnostica, Uppsala, Sweden) with a correlation coefficient of $<10 \%$.

\section{DATA ANALYSIS}

Comparisons between baseline nasal symptoms (study day -14) and nasal symptoms during the pollen season were examined by the Friedman test and the Wilcoxon signed rank test. Comparisons of the sputum levels of $\alpha_{2}$-macroglobulin and ECP, respectively, between observations before and during the pollen season were examined by the Wilcoxon signed rank test. A p value of less than 0.05 was considered significant. Furthermore, median differences with $95 \%$ confidence intervals (CI) were calculated. Data are presented as mean (SE) values.

\section{Results}

The seasonal birch pollen exposure was associated with nasal symptoms of allergic rhinitis (fig 1). These symptoms were significantly increased on study days $5,6,7,9,13,15,19$, $22,23,24$, and 26 ( $p$ values $<0.05$ ).

Increased bronchial responsiveness during the pollen season was demonstrated. At the individual cumulative dose of histamine that could be repeated at both occasions (586 $(157) \mu \mathrm{g})$ the $\mathrm{FEV}_{1}(\%$ baseline $)$ was $87(2) \%$ 


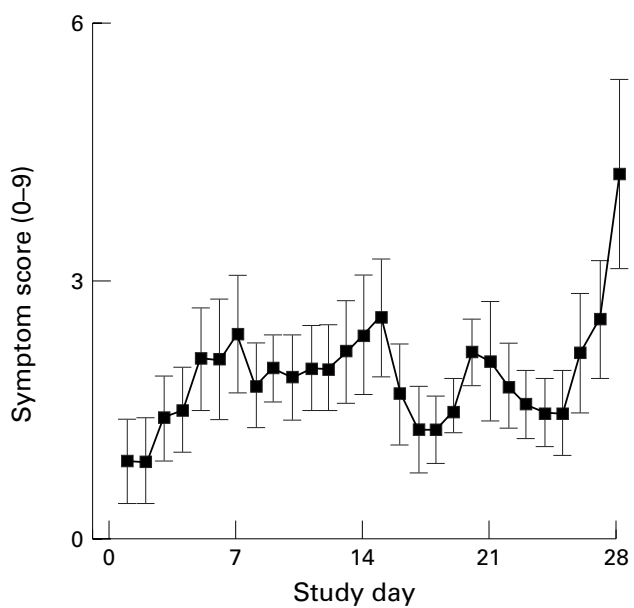

Figure 1 Nasal symptoms of allergic rhinitis (score 0-9) recorded during the study period. The scores revealed a moderate birch pollen season. Sputum was induced before (study day -14 (4) days) and during (study day 21 (2) days) the pollen season.
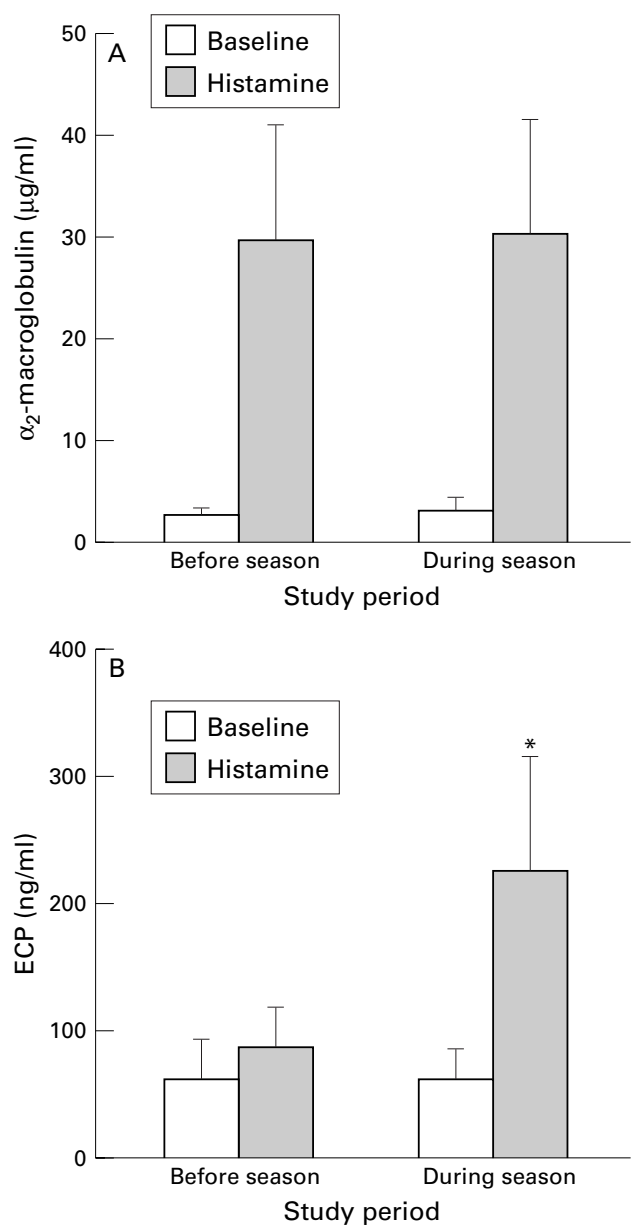

Figure 2 Sputum levels of $(A) a_{2}$-macroglobulin and (B) ECP in samples of induced sputum obtained before and during the pollen season. Induced sputum was carried out both at baseline and after challenge with histamine. Histamine increased sputum levels of bulk plasma ( $a_{2}-$ macroglobulin) before as well as during the pollen season. Sputum levels of ECP were greater during the season than before the season after combined induction of exudation ( $\alpha_{2}-$ macroglobulin) and sputum, but did not change otherwise. ${ }^{\star} p<0.05$. before the season and 77 (3)\% during the season $(\mathrm{p}<0.05)$. The median difference was $9 \%$ (95\% CI -3 to $26 \%$ ).

The total doses of histamine administered were 937 (217) $\mu \mathrm{g}$ and 912 (247) $\mu \mathrm{g}$ before and during the season, respectively. These doses of histamine produced significantly increased sputum levels of $\alpha_{2}$-macroglobulin compared with baseline both before the pollen season $(\mathrm{p}<0.01$; median difference $18.03 \mu \mathrm{g} / \mathrm{ml}(95 \%$ CI -0.13 to 54.16$)$ ) and also during the pollen season $(\mathrm{p}<0.01$, median difference $17.76 \mu \mathrm{g} /$ $\mathrm{ml}(95 \%$ CI 1.37 to 58.50$))$. The baseline levels of $\alpha_{2}$-macroglobulin and the magnitude of the exudative response were similar before and during the season (fig 2A). Histamine did not affect the sputum levels of ECP before the pollen season (fig 2B). However, histamine produced a fivefold increase in the mean levels of ECP during the pollen season (223.7 (94.9) $\mathrm{ng} / \mathrm{ml}$ ) compared with before the season (45.9 (15.8) ng/ml) ( $<<0.05$, median difference $8.2 \mathrm{ng} / \mathrm{ml}$ (95\% CI 0.4 to 562.0); fig 2B).

\section{Discussion}

We have found increased sputum levels of ECP, together with increased bronchial responsiveness, in patients with no history of asthma but who suffer from seasonal allergic rhinitis. It is of particular note that the increased sputum ECP levels were evident only after induced bronchial exudation of plasma. These data suggest that a degree of eosinophilic inflammation with increased baseline release of granular proteins into the mucosal tissue, rather than into the airway lumen, occurs in the bronchi of these patients.

Histamine inhalations may be employed for several purposes. The development of bronchial hyperresponsiveness to methacholine in seasonal rhinitis ${ }^{78}$ is consistent with the present finding of greater effects on $\mathrm{FEV}_{1}$ of the individually repeatable doses of histamine during the season compared with before the season. Histamine inhalations, but not methacholine, ${ }^{9}$ may further serve to induce acute bronchial exudation of bulk plasma. This difference is confirmed in this study and is in agreement with previous data obtained in healthy volunteers. ${ }^{9}$ Since the mean total dose of histamine did not differ much between the two challenge periods, this mucosal response could also reflect the bronchovascular exudative responsiveness. ${ }^{10}$ It is not known whether the exudative responsiveness is altered by bronchial diseases. However, we have previously reported that the nasal mucosa may develop exudative hyperresponsiveness to histamine in patients who suffer from seasonal allergic rhinitis. ${ }^{13}$ The present finding of an unchanged degree of exudation of $\alpha_{2}$-macroglobulin thus suggests that any marked exudative hyperresponsiveness did not occur during the season in the bronchi of these patients.

Before the season the 11-fold acute increase in sputum $\alpha_{2}$-macroglobulin levels was not associated with any increase in ECP levels, whereas during the season the ninefold increase in sputum $\alpha_{2}$-macroglobulin levels was associated with a significant (fivefold) increase 
in sputum ECP content. Since there is no known mechanism by which histamine itself could have acutely increased sputum ECP levels, the present data may indeed reflect plasma exudation induced movement of ECP from the bronchial mucosa into the lumen. Circulating ECP levels, even when increased in allergic disease, ${ }^{14}$ are less than the present sputum levels, which indicates that the plasma component is not important here and supports the possibility of exudation induced transport of tissue molecules into the airway lumen. We have previously observed that interleukin (IL)-6, a cytokine that is known to be bound by $\alpha_{2}$-macroglobulin, ${ }^{12}$ promptly appears together with $\alpha_{2}$-macroglobulin in nasal surface liquids at topical nasal challenge with histamine. ${ }^{15}$ Preliminary data further suggest that nasal histamine challenge increases mucosal content of ECP in the nose of children with allergic rhinitis. ${ }^{16}$ Importantly, in the latter study any contribution of baseline lavage fluid levels of ECP was ruled out. ${ }^{16}$ Hence, in both the nasal and bronchial mucosa acute exudation of bulk plasma may transiently reduce tissue levels of released ECP by bringing this protein to the lumen. This, we believe, is a more likely explanation of the present observation than the speculation that eosinophil inflammation had suddenly increased during the season in the brief interval (48 hours) between the two inductions in this study. Further investigations seem warranted to shed light on several facets of the present phenomenon. However, the pragmatic aspect is that inhalation challenge induced plasma exudation may be useful in studies of bronchial mucosal indices of eosinophilic inflammation. It is also inferred that information about exudative activity may be required to interpret properly the appearance of such indices in the lumen and, equally, to appreciate the potential for depletion of those same indices from airway tissue samples that may be examined along with the luminal material.

In this study eosinophil cell rupture produced by freezing of whole sputum samples might have contributed to the detected ECP levels. However, since we could not detect any seasonal increase in sputum ECP levels without the histamine challenge induced exuda- tion, it appears likely that the increased ECP levels reflected plasma exudation (not cellular "exudation") associated events rather than changes in luminal cell and cell debris content.

In conclusion, by employing induced plasma exudation together with induced sputum, this study has identified eosinophilic "inflammation" in the bronchi of patients with seasonal allergic rhinitis.

This study was supported by the Swedish Medical Research Council (projects 8308 and 10841), the Varrdal Foundation, and the Swedish Association against Asthma and Allergy. We thank Maria Johansson for expert bioanalytical work and Lena Glans for expert laboratory assistance.

1 Persson CGA, Svensson C, Greiff L, et al. Use of the nose to study the inflammatory response in the respiratory tract study the inflammatory response in the
(editorial). Thorax 1992;47:993-1000.

2 Frigas E, Gleich GJ. The eosinophil and the pathophysiology of asthma. F Allergy Clin Immunol 1986;77:527-37.

3 Pedersen PA, Weeke ER. Asthma and allergic rhinitis in the same patients. Allergy 1983;38:25-9.

4 Kapsali T, Horowitz E, Diemer F, et al. Rhinitis is ubiquitous in allergic asthmatics (abstract). $\mathcal{F}$ Allergy Clin Immunol 1997;99:S138.

5 Pizzichini E, Pizzichini MMM, Efthimiadis A, et al. Measuring airway inflammation in asthma: eosinophils and eosinophilic cationic protein in induced sputum compared with peripheral blood. F Allergy Clin Immunol 1997;99:539-44.

6 Gleich GJ, Kay AB, eds. Eosinophils in allergy and inflammation. New York: Marcel Dekker, 1994.

7 Henriksen JM, Wenzel A. Effect of intranasally administered corticosteroid (budesonide) on nasal obstruction, mouth breathing, and asthma. Am Rev Respir Dis 1984;130:1014-8.

8 Aubier M, Levy J, Clerici C, et al. Different effects of nasal and bronchial glucocorticosteroid administration on bronchial hyperresponsiveness in patients with allergic rhinitis. Am Rev Respir Dis 1992;146:122-6.

9 Haldorsdottir H, Greiff L, Wollmer P, et al. Effects of inhaled histamine, methacholine and capsaicin on sputum levels of $\alpha_{2}$-macroglobulin. Thorax 1997;52:964-8.

10 Persson CGA, Erjefält JS, Andersson M, et al. Extravasation, lamina propria flooding and lumenal entry of bulk plasma exudate in mucosal defence, inflammation and repair. Pulmonol Pharmacol 1996;9:129-39.

11 Peterson CG, Venge P. Interaction and complex-formation between the eosinophil cationic protein and $\alpha_{2}$-macrobetween the eosinophil cationic prote
globulin. Biochem $\mathcal{7} 1987 ; 245: 781-7$.

globulin. Biochem $\mathcal{F} 1987 ; 245: 781-7$.
12 James K. Interactions between cytokines and $\alpha_{2}$ James K. Interactions between cytokines
macroglobulin. Immunol Today 1990;11:163-6.

13 Svensson C, Andersson M, Greiff L, et al. Exudative hyperresponsiveness of the airway microcirculation in seasonal allergic rhinitis. Clin Exp Allergy 1995;25:942-50.

14 Rak S, Löwhagen O, Venge P. The effect of immunotherapy on bronchial hyperresponsiveness and eosinophil cationic protein in allergic patients. F Allergy Clin Immunol 1988;82: 470-80.

15 Persson CGA, Alker U, Andersson M, et al. Histamine challenge-induced 'lamina propria lavage' and mucosal output of IL-6 in human airways. Eur Respir f 1995;8:125s.

16 Greiff L, Andersson M, Linden M, et al. Mucosal output of $\alpha_{2}$-macroglobulin and eosinophil cationic protein (ECP) in allergic rhinitis in children (abstract). Am f Respir Crit Care Med 1997;155:A979. 